\title{
Examination of the Itch Response from the Raphides of the Fishtail Palm Caryota mitis
}

\author{
Diane S. Snyder, ${ }^{1}$ George M. Hatfield, ${ }^{2}$ And Kenneth F. Lampe ${ }^{3}$ \\ Departments of Dermatology and Pharmacology, University of Miami, School of Medicine, Miami, \\ Florida 33101, and College of Pharmacy, University of Michigan, Ann Arbor, Michigan 19380
}

Received July 6, 1978; accepted September 26, 1978

\begin{abstract}
Examination of the Itch Response from the Raphides of the Fishtail Palm Caryota mitis. Snyder, D. S., Hatfield, G. M., and Lampe, K. F. (1979). Toxicol. Appl. Pharmacol. 48, 287-292. The raphides in the mature fruit of the fishtail palm Caryota mitis Lour. were isolated by mechanical separation. These were shown by X-ray crystal analysis to be calcium oxalate monohydrate (Whewellite). The application of an aqueous suspension of the raphides to intact human skin results in an immediate, severe itch sensation. An investigation of this phenomenon appears to indicate that this is due solely to a mechanical action of the calcium oxalate needle and not to the previously postulated action of organic toxins or enzymes introduced through the skin by the penetrating action of the raphides.
\end{abstract}

Calcium salts are encountered frequently in discrete crystalline form throughout the plant kingdom. Indeed, needles (raphides) of calcium oxalate were among the first objects to be observed with a microscope; Leeuwenhoek described the raphides which occur in Arum in a letter written to H. Oldenberg on August 14, 1695 (Arnott and Pautard, 1970). Most toxicological interest concerning these calcium oxalate crystals has centered on the family Araceae (containing Dieffenbachia, Philodendron, Monstera, Caladium, Arum, etc.) which, when uncooked may cause an intense painful burning sensation in the mouth. These plants are also respon-

\footnotetext{
'Department of Dermatology, University of Miami, School of Medicine, Miami, Fla. Current address: 1181 King Rd. West Chester, Pa. 19380.

${ }^{2}$ College of Pharmacy, University of Michigan, Ann Arbor, Mich.

${ }^{3}$ Department of Pharmacology, University of Miami, School of Medicine, Miami, Fla. To whom requests for reprints should be sent.
}

sible for a nonallergic occupational contact dermatitis among florists and agricultural workers.

For some years, a modest controversy has existed as to whether the irritant action of these plants was due solely to a mechanical action of the raphides or if organic toxins or enzymes gained entry through the skin and mucosa by means of the penetrating action of the needles and were the actual offenders (Barnes and Fox, 1955; Manno et al., 1967; Martin and Martin, 1977; Van Heijst et al., 1977; Winek, 1975). We elected to reexamine the nature of the irritant action employing the more readily accesible raphides occurring in the mature fruit of the fishtail palm Caryota mitis Lour. This palm is in common horticultural use as an ornamental in tropical areas of the United States and in greenhouse collections elsewhere. The dermatological and buccal mucosa irritant effects of the fruits of this palm are well known (Morton, 1971; Quisumbing, 1951). 


\section{METHODS}

\section{Isolation of Raphides}

Ripe berries of $C$. mitis (fishtail palm) were gathered during June and July at the Fairchild Tropical Garden in Miami, Florida. The berries were gently squeezed and the juice and fleshy pulp were collected. The emptied skins were rinsed with a minimal volume of distilled water and the rinses were combined with the juice and pulp. Needle-like crystals were isolated by low speed centrifugation in a table-top centrifuge. The pellet was gently resuspended in distilled water and centrifuged at low speed to separate the crystals from the plant debris. The process of suspension and centrifugation was repeated until examination with a light microscope revealed the pellet to be substantially free from extraneous plant material. All manipulations were carried out at $4^{\circ} \mathrm{C}$.

\section{Evaluation of Itch Production by Raphides}

A stock suspension containing raphides in distilled water $(3.4 \mathrm{mg} / \mathrm{ml})$ was tested qualitatively for its ability to produce an itch response (equivalent to pain on mucosa) on the volar surface of the forearms of volunteers who were free from skin disease. A $30-\mu 1$ aliquot of the suspension was applied to the intact, normal skin surface and gently rubbed in with five circular motions over the site of application. The production of an itching sensation within 2 min of application was regarded as a positive response. In some instances, test material was applied to skin which had first been scarified with a needle to eliminate the barrier property of the stratum corneum.

\section{Manipulation of Raphides}

Active raphides which could produce an itch response were exposed to selected chemical reagents in order to determine the nature of the itch-producing factor and the solubility of the crystals. After a short ( $20 \mathrm{~min}$ ) and a longer ( 24 to $48 \mathrm{hr}$ ) exposure to a reagent, the raphides were removed, and washed with distilled water, and both the solid residue and the supernatant fraction were tested for their ability to cause itching on intact skin. If no itch response was elicited, the fraction was tested on scarified skin.

The effect of various physical manipulations on the activity of the raphides was also evaluated.

All chemically and physically manipulated raphides were examined by light microscopy. Selected raphides were examined by scanning electron microscopy.

\section{Chemical Analysis of Raphides}

The raphides were analyzed for the presence of elements having an atomic weight of 11 or higher using a JSM-U3 scanning electron microscope equipped with an X-ray detector and multichannel analyzer. An accelerating voltage of $15 \mathrm{kV}$ was utilized and the total X-ray flux was $1000 \mathrm{cps}$. The specimen for analysis was mounted on a graphite stub with carbon paint (Tube Koat).

$\mathrm{X}$-ray crystal analysis was conducted using an $\mathrm{X}$-ray powder diffractometer ( $\mathrm{CuK}_{\alpha}$ radiation) equipped with a graphite monochromator and a scintillation counter. From the $2 \theta$ values obtained, the interplaner spacing $(d)$ of the crystal was obtained using the X-ray diffraction tables of Fang and Bloss (1966).

\section{RESULTS}

One kilogram of mature berries yielded $500 \mathrm{mg}$ of solid, white needles which tapered sharply to a point at both ends (Fig. 1). The raphides ranged in length from 100 to $500 \mu \mathrm{m}$ with the majority measuring between 250 to $400 \mu \mathrm{m}$. The length-to-width ratio varied between 40 and 50 to 1 . Most had a diameter from 6 to $9 \mu \mathrm{m}$. No evidence of prominent barbs or grooves on these raphides was observed (Fig. 2). This observation was in contrast to that reported for Xanthosoma sagittifolium where these features are distinctive (Sakai et al., 1972).

The solubility properties of the raphides suggested they were composed of calcium oxalate $\cdot x \mathrm{H}_{2} \mathrm{O}$. They were insoluble in water, glacial acetic acid, $1 \mathrm{~N} \mathrm{NaOH}, 1 \mathrm{~N}$ $\mathrm{HCl}$; soluble in $3 \mathrm{~N}^{-N_{3}}, 3 \mathrm{~N} \mathrm{HCl}$, and slowly soluble in neutral EDTA. This was supported by the electron microprobe $X$-ray analysis which showed peaks at $3.65(I=$ $100)$ and $3.97 \mathrm{KeV}(I=20)$ corresponding to the $\mathrm{K}_{\alpha}(3.69)$ and $K_{\beta}(4.01 \mathrm{KeV})$ of calcium (Liebhafsky et al., 1972). No other elements of atomic No. 11 or greater were detected. The X-ray crystal analysis (Table 1) was consistent with calcium oxalate monohydrate (Whewellite) (Committee on Powder Diffraction Standards, 1976).

Freshly isolated raphides produce an intense itch within 8 to $10 \mathrm{sec}$ on skin contact. The duration of the response is usually 10 to $15 \mathrm{~min}$, but the duration is directly related to the quantity of raphides applied. The duration of the itch can be shortened if the raphides are physically removed from the skin, e.g., by applying and removing adhesive tape at the application site. In several 


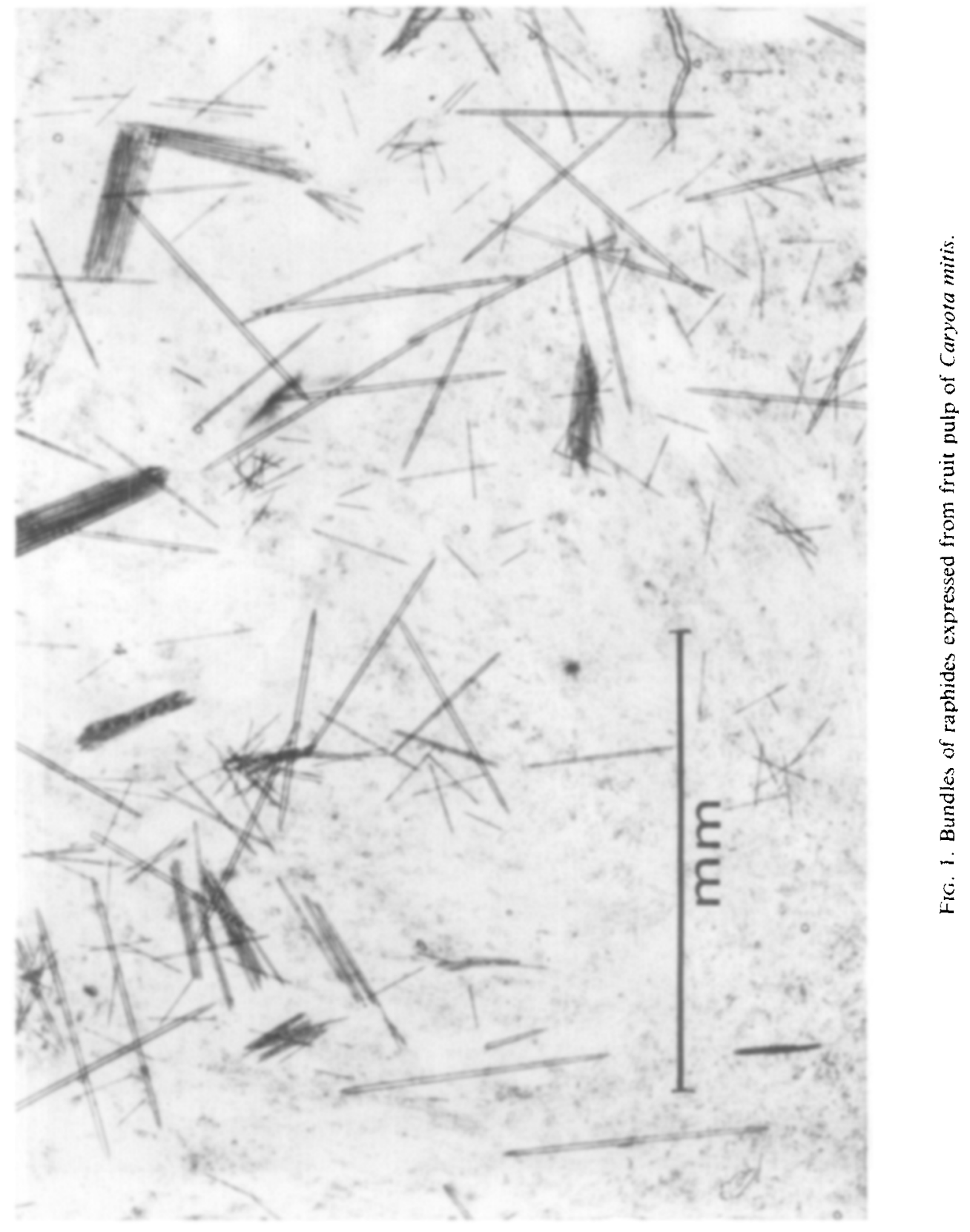




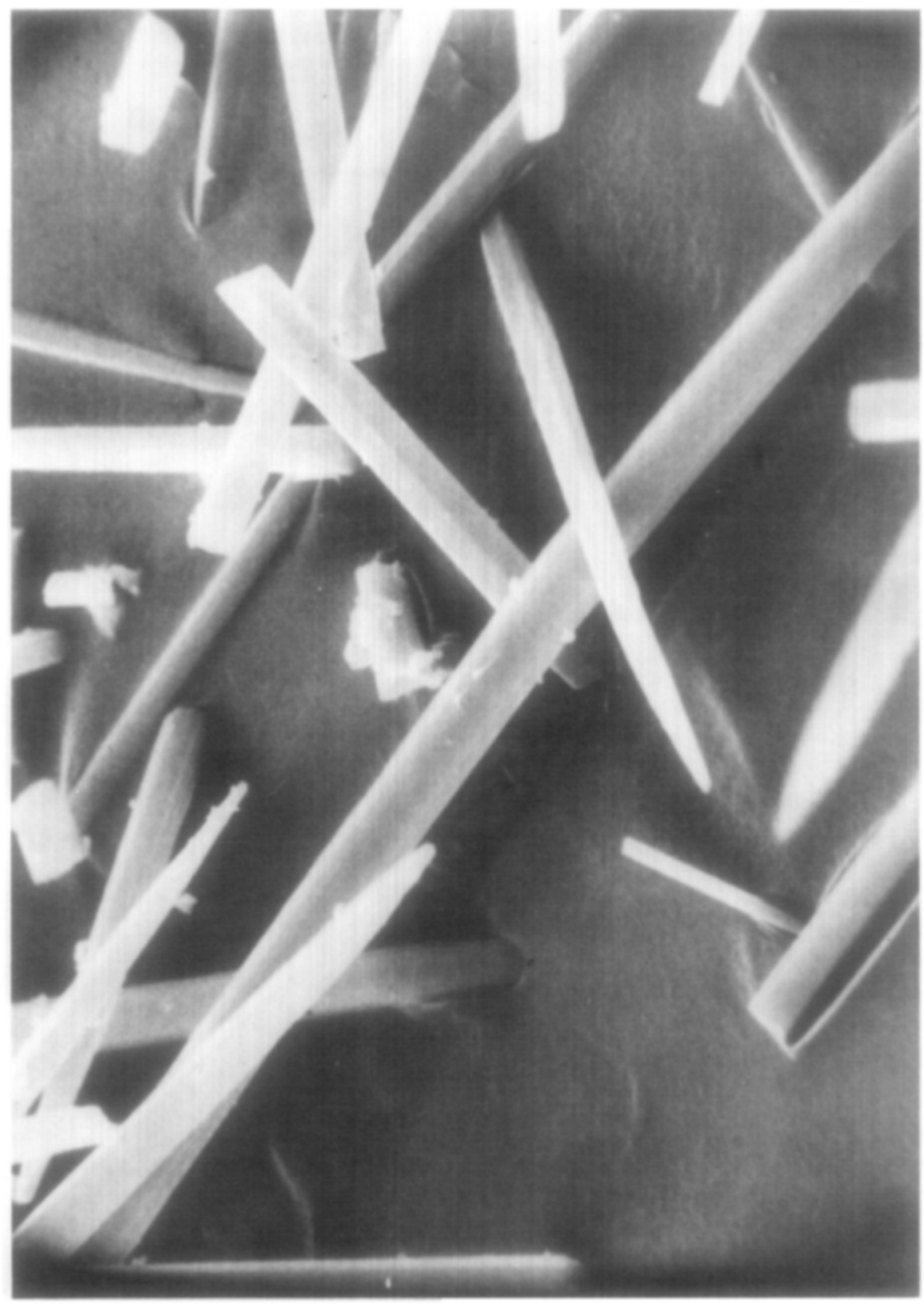


TABLE 1

X-Ray Powder Diffraction Analysis of Raphides

\begin{tabular}{ccccc}
\hline Obsd $2 \theta$ & $\begin{array}{c}d \\
(\AA)\end{array}$ & Obsd $/ I / I_{\mathbf{1}}$ & $\begin{array}{c}\text { Std } d \\
(\AA)^{a}\end{array}$ & Std $/ / / I_{1}{ }^{a}$ \\
\hline 14.73 & $6.01^{b}$ & 75 & 5.93 & 100 \\
& & & 5.79 & 30 \\
24.55 & 3.63 & 100 & 3.65 & 70 \\
30.25 & 2.95 & 56 & 2.97 & 45 \\
36.15 & 2.48 & 37 & 2.49 & 18 \\
38.40 & 2.34 & 58 & 2.36 & 30 \\
\hline
\end{tabular}

${ }^{a}$ Calcium oxalate monohydrate, ASTM Card 20-231 (Committee on Powder Diffraction Standards).

${ }^{b}$ Unresolved doublet.

volunteers mild redness and swelling persisted for 8 to $12 \mathrm{hr}$ at the site of raphide application even when scratching of the area was precluded.

Raphides could still produce an itch response even after they were stored for 5 years in distilled water at $4^{\circ} \mathrm{C}$. These raphides required approximately $30 \mathrm{sec}$ to produce a moderate itch. An identical sample, stored dry at room temperature for 5 years, was inactive, and the raphides had become friable.

The elicitation of an itch response was always associated with intact raphides and could not be demonstrated in the original supernatant fraction or in the various supernatant fractions which resulted from attempted extractions with: water, $0.9 \% \mathrm{NaCl}$ acetone, ethanol, chloroform: methanol $(2: 1)$, or benzene. Following any of these solvent treatments, the solid residue retained its ability to produce an itch sensation. Exposure to common enzyme inactivators, $10^{-2} \mathrm{M} \mathrm{Cu}^{2+}, 10^{-2} \mathrm{M} \mathrm{Hg}^{2+}, 10^{-2} \mathrm{M} \mathrm{CN}^{-}$, or $1 \%$ sodium lauryl sulfate, also could not affect the response. Activity was lost only when the raphides were physically or chemically disrupted, as by: pulverization, sonic disruption $(10 \mathrm{sec})$, repeated freezing-thawing, vigorous boiling in water (30 $\mathrm{min})$, or by treatment with $10^{-2} \mathrm{M}$ EDTA solution at neutral $\mathrm{pH}$.

\section{DISCUSSION}

Raphides of calcium oxalate are found quite commonly in plants (Arnott and Pautard, 1970) and in some marine algae (Friedman et al., 1972). Toxic response has been reported following human contact with these raphides. The irritation and itching caused by the raphides isolated from the mature fruit of $C$. mitis seem to be due solely to the mechanical action of the intact needles on the skin. No evidence was found for a factor dissociable from the raphides which could produce this itch response. It was not possible to prevent the response by exposing the raphides to standard enzyme inactivating reagents. On the other hand, simple pulverization was associated with a total loss of activity, even when the ground crystals were applied to scarified skin.

Mechanical irritation of the skin, as evidenced by itching and mild inflamation, has been reported to be produced by glass wool fibers with diameters greater than $5.3 \mu \mathrm{m}$ (Heisel and Hunt, 1968). In the case of the glass fibers any association with toxic substances can be eliminated from consideration. The majority of raphides which we isolated from C. mitis had a diameter of 6 to $9 \mu \mathrm{m}$, which places them in the irritating range described for glass fibers.

A mechanical irritation due to intact calcium oxalate crystals would seem to be the simplest explanation for the production of pain and itch by the raphides of $C$. mitis. Such an explanation should probably be sought for raphides of other plant sources. in particular, from the family Araceae.

\section{ACKNOWLEDGMENTS}

We wish to thank Mr. Sheldon Suskauer for his technical assistance. The plant material was supplied by the Fairchild Tropical Garden, Miami, Fla. We wish to thank Dr. Jack B. Fisher and Mr. Stanley C. Keim of that institution for their aid. The scanning electron microscopy was conducted through the courtesy of the Dow Chemical Company of Midland, Mich. 


\section{REFERENCES}

Arnott, H. J., and Pautard, F. G. E. (1970). Calcification in Plants. In Biological Calcification Cellular and Molecular Aspects (H. Schraer, ed.), pp. 375-466. Appleton-Century-Crofts, New York.

BarNes, B. A., AND Fox, L. E. (1955). Poisoning with Dieffenbachia. J. Hist. Med. All. Sci. 10, 173181.

Joint Committee on Powder Diffraction StanDARDS 1976. Powder Diffraction File Search Manual, Publ. SMA-26. Swarthmore, Pa.

FANG, J. H., AND Bloss, F. D. (1966). $X$-Ray Diffraction Tables. Southern Illinois Univ. Press, Carbondale.

Friedman, E. I., Roth, W. C., Turner, J. B., AND MCEWEN, R. S. (1972). Calcium oxalate crystals in the aragonite-producing green alga Penicillus and related gencra. Science 177, 891-93.

Heisel, E. B., and HUNT, F. E. (1968). Further studies in cutaneous reactions to glass fibers. Arch. Environ. Health 17, 705-11.

Liebhafsky, H. A., Pfeiffer, H. G., Winslow, E. H., and ZEMANY, P. D. (1972). X-Rays, Electrons and
Analytical Chemistry, p. 522. Wiley-Interscience, New York.

Manno, J. E., Fochtman, F. W., and Winek, C. L. (1967). Toxicity of plants of the genus Dieffenbachia. Toxicol. Appl. Pharmacol. 10, 55-56.

Martin, M., and Martin, Ch. (1977). Accident caustique buccopharyngé provoqué par le Dieffenbachia picta. J. Franc. Oto-Rhino-Laryngol. 26, $715,719$.

Morton, J. F. (1971). Plants Poisonous to People in Florida and Other Warm Areas, pp. 63-64. Hurricane House, Miami.

Quisumbing, E. (1951). Medicinal Plants of the Philippines. Tech. Bull. 16, p. 126. Dept. Agr. Nat. Res., Republic of the Philippines, Manila.

SAKai, W. S., Hanson, M., and Jones, R. C. (1972). Raphides with barbs and grooves in Xanthosoma sagittifolium (Araceae). Science 178, 314-15.

Van Heisst, A. N. P., Pikaar, S. A., and Van Kesteren, R. G. (1977). Dieffenbachia van pijlgif tot kamerplant. Ned. Tijdschr. Geneesk. 121, 1996-99.

WINEK, C. L. (1975). Editorial comment-Dieffenbachia. Poison Penlett. 2(4), 1. 